\title{
AUDIT TEKNOLOGI INFORMASI PADA DEALER MOBIL XYZ DI BANDAR LAMPUNG DENGAN MENGGUNAKAN PENDEKATAN COBIT 4.1
}

\author{
${ }^{1}$ Lilis Oktaviani Sirait dan ${ }^{2}$ Tristiyanto \\ ${ }^{1}$ Jurusan Ilmu Komputer FMIPA Unila \\ ${ }^{2}$ Jurusan Ilmu Komputer FMIPA Unila
}

Email : ${ }^{1}$ lilisoktavianisirait@gmail.com ${ }^{2}$ tristiyanto.1981@fmipa.unila.ac.id

\begin{abstract}
Information technology is growing rapidly and greatly influences to improving the effieciency and effectiveness of business activities in developing the company. In this case, an information technology audit is needed to ensure the existing information technology, that has been already satisfy the common control standards and has the ability to compete in the business world. The purpose of this research is to evaluate the assessment and to make recommendations based on the analysis maturity level of IT in Car Dealer XYZ in Bandar Lampung according to the framework COBIT 4.1. Standard of COBIT 4.1 has parameters that can aid the assessment of an enterprise using a maturity model. This research finds that the result of maturity level of Car Dealer XYZ in Bandar Lampung is 4.02. This shows that Information Technology has been updated well where the procedures and policies have been done effectively, monitored and there are corrective actions are taken.
\end{abstract}

Keywords : Information technology, maturity level, recommendations, control objectives for information and related technology (COBIT)

\section{Pendahuluan}

Kemajuan teknologi informasi yang ada sangat berpengaruh terhadap peningkatan efisiensi serta efektivitas kegiatan bisnis dalam mengembangkan perusahaan. Kegiatan bisnis akan berhasil apabila teknologi informasi bisa diselaraskan dengan kegiatan perusahaan [1].

Teknologi informasi di Dealer Mobil XYZ Bandar Lampung hampir seluruhnya memanfaatkan TI dalam berlangsungnya kegiatan di perusahaan ini. TI menjadi alat bantu yang dapat mempermudah kinerja staf beserta proses operasional di perusahaan [2]. Salah satunya yaitu memberikan layanan service kepada pelanggan secara terstruktur. Dalam menjalani bisnis ini, perusahaan harus update dalam mengikuti perkembangan jaman khususnya mengenai TI.

Namun, dalam pemanfaatan TI untuk kegiatan bisnis harus dilakukan evaluasi dalam bentuk audit terhadap TI. Hal ini dilakukan untuk mencegah risiko yang muncul di masa mendatang dan kegiatan bisnis dapat berjalan dengan baik [3]. Audit terhadap TI dilakukan untuk mengetahui apakah TI yang telah berjalan sudah memenuhi standar kontrol umum atau belum.

Secara umum, audit teknologi informasi merupakan proses pengumpulan data dari semua kegiatan informasi perusahaan yang akan dilakukan evaluasi dan pengawasan mengenai teknologi informasi perusahaan untuk mencapai targetnya [4]. 
Penelitian ini menggunakan COBIT 4.1 sebagai framework IT untuk melakukan audit TI dan dengan menggunakan maturity models. COBIT 4.1 menyediakan framework dan parameter yang dapat membantu penilaian resiko, mengevaluasi kinerja teknologi informasi dan mengelola resiko perusahaan dengan tepat [5].

Maturity models dalam COBIT 4.1 sebagai alat ukur dalam mengetahui kondisi proses TI yang digunakan Dealer Mobil XYZ Bandar Lampung saat ini. Maturity models dikelompokan dari level 0 (nol) atau non-existent (belum tersedia) hingga level 5 (lima) atau optimized (teroptimasi) [6]. Level tersebut dikelompokkan dengan tujuan supaya pihak manajemen dapat dengan mudah memahami dan mengidentifikasi setiap proses teknologi informasi yang ada dalam suatu perusahaan [7].

Berdasarkan uraian dan latar belakang tersebut, maka penulis memutuskan untuk melakukan penelitian pada Dealer Mobil XYZ Bandar Lampung dengan judul "Audit Teknologi Informasi pada Dealer Mobil XYZ Bandar Lampung dengan Menggunakan Pendekatan COBIT $4.1^{\prime \prime}$.

Adapun batasan dalam penelitian ini yaitu audit yang dilakukan hanyalah audit terhadap TI pada Dealer Mobil XYZ Bandar Lampung serta framework IT yang digunakan mengacu pada COBIT 4.1. Oleh karena itu, dalam penelitian ini akan membahas mengenai hasil analisa maturity level teknologi informasi dan rekomendasi apa yang dapat diberikan berdasarkan hasil analisa tersebut pada Dealer Mobil XYZ Bandar Lampung.

\section{Metode Penelitian}

Penulis melakukan tinjauan terhadap teknologi informasi di Dealer Mobil XYZ Bandar Lampung sebagai objek penelitian ini. Data yang diperoleh berupa data sekunder serta kondisi TI di perusahaan. Pengumpulan data dalam penelitian ini diperoleh dari pihak yang terkait yaitu bagian TI di Dealer Mobil XYZ Bandar Lampung.

Adapun metode pengumpulan data yang digunakan yaitu dengan observasi, interview, kuisioner, dan studi literatur. Kuisioner terdiri dari empat domain yaitu domain PO (Planning and Organizing), AI (Acquisition and Implementation), DS (Delivery and Support), dan ME (Monitoring and Evaluation). Sedangkan instrumen diukur dengan menggunakan skala maturity level dari 0 (non existent) sampai dengan 5 (optimized) [6].

Tahap pengumpulan data selesai dilakukan kemudian mulai membuat dan mengisi form pertanyaan dalam bentuk kuisioner. Dalam mendukung penelitian ini, maka dibuat kuisioner dengan tujuan untuk melakukan identifikasi dan analisis terhadap kondisi TI Dealer Mobil XYZ Bandar Lampung.

Berdasarkan analisa dan identifikasi terhadap kondisi TI Dealer Mobil XYZ Bandar Lampung diperoleh, kemudian memperoleh nilai maturity level sebagai pencapaian dari tiap proses TI yang dilakukan audit [8]. Analisis tersebut digunakan untuk menemukan akar masalah yang ada, resiko yang mungkin akan muncul dan memberikan rekomendasi sebagai perbaikan terhadap masalah di tiap proses TI yang telah dianalisis.

Pelaksanaan penelitian ini dilakukan berdasarkan kerangka berpikir penelitian sebagai acuan untuk melakukan audit. Penjelasan kerangka berpikir penelitian diuraikan seperti pada Gambar 1. 


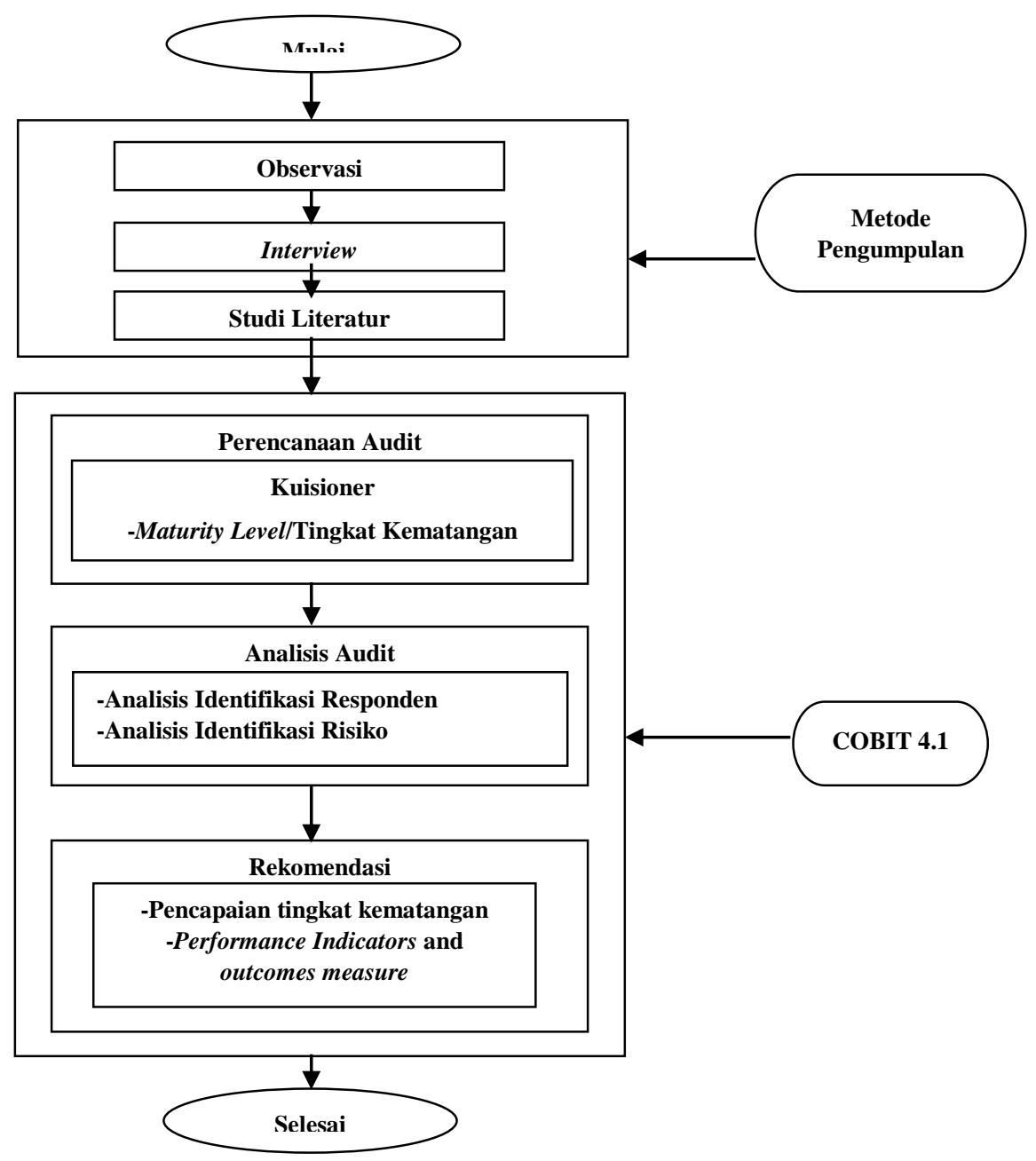

Gambar 1. Kerangka Berpikir Penelitian

\subsection{Tahap Perencanaan Audit}

Adapun tahap dalam perencanaan audit yaitu sebagai berikut.

1. Mengumpulkan data berupa data sekunder perusahaan

2. Melakukan mapping dengan mengelompokkan data sekunder yaitu dengan mendefinisikan data berdasarkan perspektif, tujuan bisnis, tujuan TI dan menghasikan output proses TI.

3. Melakukan penghitungan banyaknya domain yang muncul selama proses mapping TI untuk memperoleh range.

4. Mengelompokkan range tiap proses TI yang ada berdasarkan level low, medium dan high [9].

5. Mengolah data dengan melakukan analisis berdasarkan perhitungan maturity level yang diperoleh pada tiap proses TI.

6. Pembuatan rekomendasi berdasarkan hasil analisa maturity level tiap proses TI yang ada.

\subsection{Teknik Pengolahan Data dan Analisis Data}


Teknik pengolahan data dilakukan untuk memperoleh informasi dari pihak TI terkait implementasi TI dengan admin di perusahaan yaitu mengisi kuisioner dan melakukan interview [10]. Setiap pernyataan yang terdapat dalam kuisioner, penulis mengacu pada pernyataan dari COBIT 4.1. Domain yang akan dianalisis merupakan hasil dari penyeleksian pada mapping iterasi kedua.

Pernyataan mengenai profil perusahaan berdasarkan pada hasil iterasi kedua berisi misi, tujuan, rencana strategis yang akan dilakukan mapping. Pernyataan tersebut diuraikan sebagai berikut.

a. Misi dari perusahaan yaitu memproduksi mobil compact bernilai terbaik dan menyediakan layanan terkait yang penting bagi peningkatan nilai stakeholder dan ramah lingkungan memiliki definisi terkait dengan perspektif pelanggan dan dipetakan pada tujuan bisnis yang penting yaitu peningkatan layanan dan orientasi terhadap pelanggan. Selanjutnya memetakan dengan tujuan TI yang penting dan menghasilkan proses TI PO8, AI4, DS1, DS2, DS3, DS4, DS7, DS8, DS10, DS13.

b. Tujuan dari perusahaan yaitu Dealer mobil XYZ Bandar Lampung terus mengembangkan usahanya untuk dapat mencapai tujuan "Sejahtera Bersama Bangsa" memiliki definisi terkait dengan perspektif pelanggan dan dipetakan pada tujuan bisnis yang penting yaitu peningkatan dan pemeliharaan fungsionalitas proses bisnis. Selanjutnya memetakan dengan tujuan TI yang penting dan menghasilkan proses TI AI1, AI2, DS7, AI6.

c. Rencana strategis kedua dari perusahaan yaitu didukung oleh outlet yang tepat sesuai produk Dealer mobil XYZ Bandar Lampung, memiliki definisi terkait dengan perspektif pelanggan dan dipetakan pada tujuan bisnis yang penting yaitu peningkatan layanan dan orientasi terhadap pelanggan. Selanjutnya memetakan dengan tujuan TI yang penting dan menghasilkan proses TI PO8, AI4, DS1, DS2, DS3, DS4, DS7, DS8, DS10, DS13.

d. Rencana strategis keempat dari perusahaan yaitu mempertahankan sinergi dan kerja sama dengan bisnis unit lain di grup Dealer mobil XYZ Bandar Lampung, memiliki definisi terkait dengan perspektif pelanggan dan dipetakan pada tujuan bisnis yang penting yaitu peningkatan dan pemeliharaan fungsionalitas proses bisnis. Selanjutnya memetakan dengan tujuan TI yang penting dan menghasilkan proses TI AI1, AI2, AI6.

e. Rencana strategis kelima dari perusahaan yaitu memperkuat kerja sama lintas lini, merapatkan barisan dan mempertahankan fighting spirit, memiliki definisi terkait dengan perspektif keuangan dan dipetakan pada tujuan bisnis yang penting yaitu peningkatan transparansi dan tata kelola perusahaan. Selanjutnya memetakan dengan tujuan TI yang penting dan menghasilkan proses TI PO1, PO4, PO10, ME1 dan ME3.

Kuisioner dalam penelitian ini membahas mengenai maturity level, indikator kinerja, penilaian control objective, dan manajemen pengetahuan. Informasi mengenai TI yang diajukan dalam bentuk kuisioner melalui interview menjadi informasi TI yang diperoleh untuk mendukung penelitian ini. Responden diminta untuk memberikan pendapatnya mengenai keberadaan investasi akan implementasi TI pada Dealer Mobil XYZ Bandar Lampung. Kuisioner tersebut tetap mengacu pada COBIT 4.1 sebagai framework TI yang digunakan sehingga proses TI dengan tiap pertanyaan memiliki keterkaitan dalam daftar interview. 


\section{Hasil Audit}

Data mengenai TI pada Dealer Mobil XYZ Bandar Lampung diperoleh dari interview, observasi, dan studi literatur. Berdasarkan pada analisis data yang telah diolah, untuk melakukan tahap mengidentifikasi antara lain menemukan akar masalah dari proses TI yang dianalisis, mencegah munculnya risiko yang mungkin akan terjadi serta memberikan rekomendasi berdasarkan masalah yang ditemukan.

Dalam identifikasi proses TI menggunakan COBIT 4.1, terdapat 18 proses TI yang merupakan hasil dari penyeleksian domain saat mapping iterasi kedua dilakukan. Adapun 7 proses TI yang berada di level 3, sedangkan 11 proses TI berada di level 4 . Hal itu berarti bahwa beberapa proses TI yang telah dilakukan audit pada Dealer Mobil XYZ Bandar Lampung menunjukkan proses penggunaan TI dapat diukur dan dijalankan serta memperhatikan resiko yang akan terjadi.

Penilaian proses TI menjadi gambaran mengenai pencapaian maturity level proses TI di perusahaan. Dengan adanya penilaian tersebut, maka perkembangan TI dapat dipantau dengan tujuan untuk mencapai nilai maturity level yang terus meningkat.

Pencapaian nilai maturity level yang diharapkan ditentukan dari pihak TI yaitu satu level di atas dari nilai maturity level saat ini. Hal ini bertujuan sebagai acuan untuk melihat sejauh mana perkembangan TI di Dealer Mobil XYZ Bandar Lampung. Penilaian dari 18 proses TI dapat dilihat dalam Tabel 1. Penilaian Current and Expected sedangkan Penilaian Current and Expected yang digambarkan dalam bentuk grafik Spiderchart pada Gambar 2. Spiderchart untuk mengetahui perbandingan dari kondisi TI di perusahaan saat ini dengan maturity level yang diharapkan.

Tabel 1. Penilaian Current and Expected

\begin{tabular}{|l|l|c|c|}
\hline \multicolumn{2}{|c|}{ Nama Proses } & Current & Expected \\
\hline PO1 & Mendefinisikan Rencana Strategi TI & 4,11 & 5 \\
\hline PO4 & Menentukan Proses TI, Organisasi dan Hubungan & 3,18 & 4 \\
\hline PO8 & Mengelola Kualitas & 3,99 & 4 \\
\hline PI1 & Mengelola Proyek & 4,35 & 5 \\
\hline AI2 & Memperoleh dan Mempertahankan Aplikasi Software & 3,77 & 4 \\
\hline AI4 & Mengaktifkan Operasi dan Penggunaan & 4,75 & 5 \\
\hline AI6 & Mengelola Perubahan & 4,05 & 5 \\
\hline DS1 & Menetapkan dan Mengelola Tingkat Layanan & 4,43 & 5 \\
\hline DS2 & Mengelola Layanan Pihak Ketiga & 4,51 & 5 \\
\hline DS3 & Mengelola Kinerja dan Kapasitas & 4,10 & 5 \\
\hline DS4 & Memastikan Layanan Berkesinambungan & 4,54 & 5 \\
\hline DS7 & Mendidik dan Melatih Pengguna & 4,18 & 5 \\
\hline DS8 & Mengelola Jadwal Layanan dan Kejadian & 3,98 & 4 \\
\hline DS10 & Mengelola Masalah & 4,03 & 5 \\
\hline DS13 & Mengelola Operasi & 4,02 & 5 \\
\hline ME1 & Memantau dan Mengevaluasi Kinerja TI & 3,52 & 4 \\
\hline ME3 & Memastikan Kepatuhan dengan Persyaratan Eksternal & 3,44 & 4 \\
\hline & & 4,02 & 4,61 \\
\hline
\end{tabular}




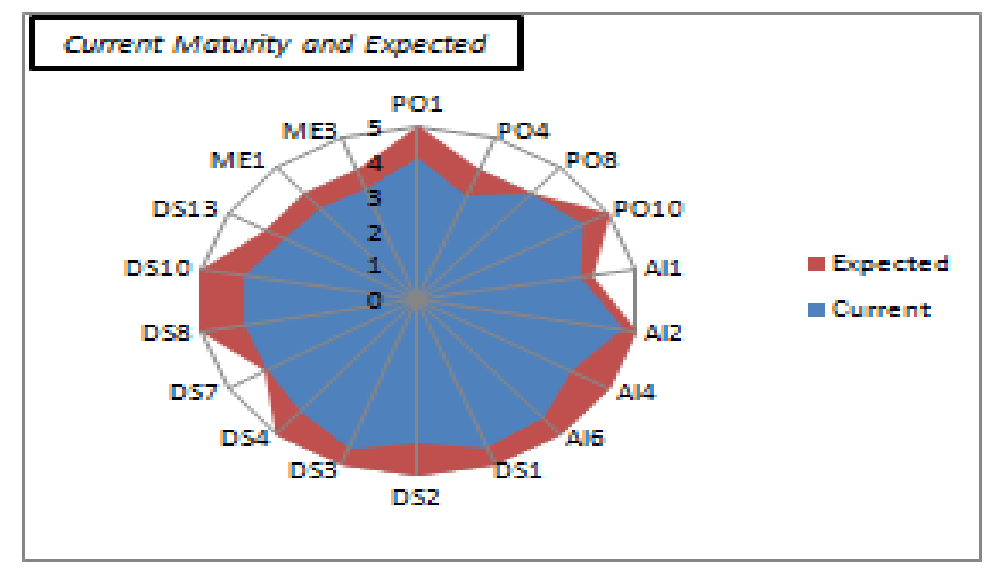

Gambar 2. Spiderchart

\section{Rekomendasi}

Berdasarkan pada gap analysis dan tabel penilaian Current Maturity and Expected, masingmasing domain yang ada pada tabel penilaian dan gap analysis akan dianalisis untuk menemukan akar masalah dan risiko yang ada pada tiap domain. Proses TI yang memperoleh nilai maturity level sebesar 3 diantaranya yaitu PO4, PO8, AI1, DS7, DS13, ME1, dan ME3. Sedangkan proses TI yang memperoleh nilai maturity level sebesar 4 diantaranya yaitu PO1, PO10, AI2, AI4, AI6, DS1, DS2, DS3, DS4, DS8, dan DS10.

Dari 18 proses TI yang dianalisis bahwa nilai maturity level yang terendah terdapat pada domain PO yaitu proses TI PO4 dalam menentukan hubungan, organisasi dan proses TI yaitu sebesar 3.18. Hal ini berarti bahwa proses perencanaan yang digunakan untuk membantu manajer, ketua tim dan anggota tim lebih ditingkatkan lagi agar sumber daya manusia bekerja lebih efektif. Nilai maturity level yang tertinggi terletak di proses TI AI2 yaitu memperoleh dan mempertahankan aplikasi software berada di level 4 yaitu mencapai 4.75. Nilai ini menunjukkan bahwa perusahaan memiliki kontrol terhadap proses dan produk sehingga matrik yang ada digunakan untuk suatu produk, proses dan pengukuran hasil.

Pada pembahasan ini, kondisi proses TI pada Dealer Mobil Bandar Lampung dapat diinterpretasikan bahwa ada beberapa hal dalam tiap domain yang perlu ditingkatkan yaitu sebagai berikut:

1. PO (Planning and Organization)

Dalam pelaksanaan proses perencanaan masih perlu ada prosedur untuk memeriksa perencanaan proses yang akan dilaksanakan. Pelaksanaan proses tersebut dilakukan di bawah pengawasan tiap manajer agar semua staf juga memiliki tanggung jawab terhadap kebutuhan organisasi.

2. AI (Acquisition and Implementation)

Keberhasilan tiap proyek menjadi tanggung jawab dan kerja sama antar staf. Hal ini dilakukan untuk menghasilkan dokumentasi yang lengkap dan bermanfaat untuk membawa perubahan yang lebih baik sesuai yang diharapkan di masa mendatang.

3. DS (Delivery and Support)

Proses perencanaan kapasitas dan kinerja harus terus didefinisikan untuk melakukan otomatisasi proses. Penilaian kinerja untuk tiap individu terus dipantau, dilaporkan dan untuk memperoleh dukungan pengetahuan disesuaikan dengan di bawah pengawasan langsung. 
4. ME (Monitoring and Evaluation)

Proses TI ini memperoleh nilai maturity level berada di level 3 (Defined) dimana kegiatan monitoring dan evaluasi terhadap kinerja TI membutuhkan proses penelusuran bukti untuk kebutuhan eksternal agar dilaksanakan dengan baik. Dimana sistem pelacakan dalam organisasi secara terpusat belum ada sehingga sangat rentan untuk ditetapkannya peraturan yang ada.

\section{Simpulan dan Saran}

Berdasarkan hasil penelitian yang telah dilakukan, dapat disimpulkan bahwa :

1. Berdasarkan audit 18 domain sesuai framework COBIT 4.1, rata-rata maturity level adalah 4,02 yang artinya TI telah dikelola dengan baik dimana prosedur dan kebijakan yang ada sudah dilakukan secara efektif, dapat dipantau dan diukur sehingga apabila terjadi kesalahan sudah memiliki prosedur untuk tindakan perbaikan yang dilakukan.

2. Pencapaian nilai maturity level dari 18 proses TI yang dianalisis, diperoleh bahwa 7 proses TI masih berada di level 3 dan sisanya berada di level 4.

3. Maturity level yang terendah dari 18 proses TI yang ada yaitu proses TI PO4 untuk menentukan proses TI, organisasi dan hubungan sebesar 3,18. Sedangkan untuk domain maturity level yang tertinggi yaitu berada pada level 4 yaitu proses TI AI2.

\section{SARAN}

Adapun saran-saran bagi peneliti selanjutnya yang dapat dilakukan adalah:

1. Audit Teknologi Informasi dalam penelitian ini berdasarkan framework COBIT 4.1 dengan menggunakan 4 domain yaitu PO, AI, DS dan ME. Penelitian selanjutnya bisa menggunakan konsep framework Val IT yang dapat digunakan untuk mengetahui seberapa besar pengaruh investasi TI terhadap kinerja di perusahaan.

2. Berdasarkan analisis yang diperoleh dari hasil audit, maka rekomendasinya yaitu menetapkan standarisasi dalam kebijakan dan prosedur dalam kegiatan pengawasan dan evaluasi yang berfokus TI pada Dealer Mobil Bandar Lampung agar dilakukan secara rutin dan konsisten sebagai perbaikan untuk perusahaan di masa mendatang.

\section{Referensi}

[1] Prasita, Andim dan Adi, Priyo Hari, Pengaruh Kompleksitas Audit dan Tekanan Anggaran Waktu terhadap Kualitas Audit dengan Moderasi Pemaham terhadap Sistem Informasi, Jurnal Ekonomi dan Bisnis, Vol. XIII, No.1, 267-285, (2007).

[2] Isa, Irwan, Evaluasi Pengontrolan Sistem Informasi. Yogyakarta: Graha Ilmu, 220 hlm, (2012).

[3] Nadhiroh, Siti Asih, "Pengaruh Kompleksitas Tugas, Orientasi Tujuan, dan Self Efficicacy Terhadap Kinerja Auditor dalam Pembuatan Audit Judgment". (Skripsi). Universitas Diponegoro, Semarang, (2010).

[4] Wahyono, Teguh, Sistem Informasi (Konsep Dasar, Analisis Desain dan Implementasi), Yogyakarta: Graha Ilmu, $150 \mathrm{hlm}$, (2004).

[5] Purwanto, Evaluasi Tata Kelola Teknologi Informasi Menggunakan Kerangka Kerja CobIT dalam Mendukung Layanan Sistem Informasi Akademik Studi Kasus: Universitas Budi Luhur. Jurnal Telematika, Vol.II, No.1, 2085-725X, (2010).

[6] ITGI, Cobit 4.1. Framework-Control-Objectives-Management Guidelines Maturity Models.USA: I.G, Institute, 213 hlm, (2007). 
[7] Gondodiyoto, Audit Sistem Informasi + Pendekatan CobIT, Jakarta: Mitra Wacana Media, 692 hlm, (2007).

[8] Yakub, Pengantar Sistem Informasi. Yogyakarta: Graha Ilmu. 182 hlm, (2012).

[9] Budiman, Arief dkk. "Perencanaan Paket. Pengembangan TIK pada Domain DS (Delivery and Support) dan ME. (Monitoring and Evaluation) Cobit di Pemerintahan Kota XYZ". (Thesis). Institut Teknologi Surabaya, Surabaya (2012).

[10]Fitrianah, Devi dan Sucahyo, Yudha Giri, Audit Sistem Informasi/ Teknologi Informasi Dengan Kerangka Kerja COBIT Untuk Evaluasi Manajemen Teknologi informasi Di Universitas XYZ. Jurnal Of Information System, Vol.IV, No.1, 243-253, (2008). 